\title{
AR Cocoa: diseño e implementación de siete estaciones de realidad: aumentada en el campus de la Universidad San Francisco de Quito
}

\section{AR Coco: design and implementation of seven Reality stations: augmented on the campus of the San Francisco University of Quito}

Fabián Varela

Universidad San Francisco de Quito, Ecuador

Cristina Muñoz

Universidad San Francisco de Quito, Ecuador

Jorge Flores

Universidad San Francisco de Quito, Ecuador

Autor para correspondencia: fvarela@usfq.edu.ec; mmunoz@usfq.edu.ec.

Fecha de recepción: 07 de Agosto 2017 - Fecha de aceptación: 15 de Marzo de 2018

\section{Resumen}

La realidad aumentada superpone el mundo virtual con el mundo real; creando un complemento de interacción en el entorno. Este artículo hace un resumen de la historia de la Realidad Virtual y Aumentada, y luego describe y analiza el proceso de diseño y producción de siete estaciones de Realidad Aumentada distribuidas alrededor del campus de la Universidad San Francisco de Quito, en Ecuador; explorando posibles interacciones entre las personas y el campus. A su vez, plantea posibles caminos de evolución de esta tecnología, así como su potencial en el contexto para el cual ha sido aplicada.

Palabras Clave: interactividad; realidad aumentada; medios digitales

\begin{abstract}
Augmented Reality superimposes the virtual world with the real world; creating an interaction plugin in the environment. This article summarizes the history of Virtual and Augmented Reality and describes and analyzes the design and production process of seven Augmented Reality stations spread around the campus of Universidad San Francisco de Quito, in Ecuador; exploring possible interactions between people and campus. At the same time, it proposes ways in which this technology can evolve as well as its potential in the context for which it has been applied.
\end{abstract}

Key words: storytelling; design thinking; animación 


\section{Antecedentes}

\section{Introducción}

Durante la primera proyección de los hermanos Lumiere, ocurrida el 28 de diciembre de 1895 en el Boulevard Des Capuchines, el novel público observó cómo un grupo de mujeres salía de una fábrica o cómo un hombre le jugaba una broma a otro hombre que regaba el césped con una manguera. Quizás, lo que más sorprendió al incipiente grupo de atentos espectadores fue cómo un tren se venía acercando a sus improvisadas butacas, causando expectación y en algunos casos, hasta temor por aquel evento. Fue esta sucesión de imágenes con percepción de movimiento, lo que podría definirse como una de los más primitivos acercamientos a una experiencia virtual.

En 1957, Morton Heilig, realizador de cine, construyó un prototipo similar a una consola de videojuegos Arcade y la nombró Sensorama.La consola proyectaba imágenes en 3D, con sonido envolvente. Además de esto, contaba con unas cámaras de aire que soplaban corrientes al usuario.

En 1966, Ivan Sutherland, Profesor de Ingeniería Eléctrica de la Universidad de Harvard, creó el HMD (Human Mounted Display).Este dispositivo era de gran envergadura y suspendía del techo del laboratorio del Profesor Sutherland.

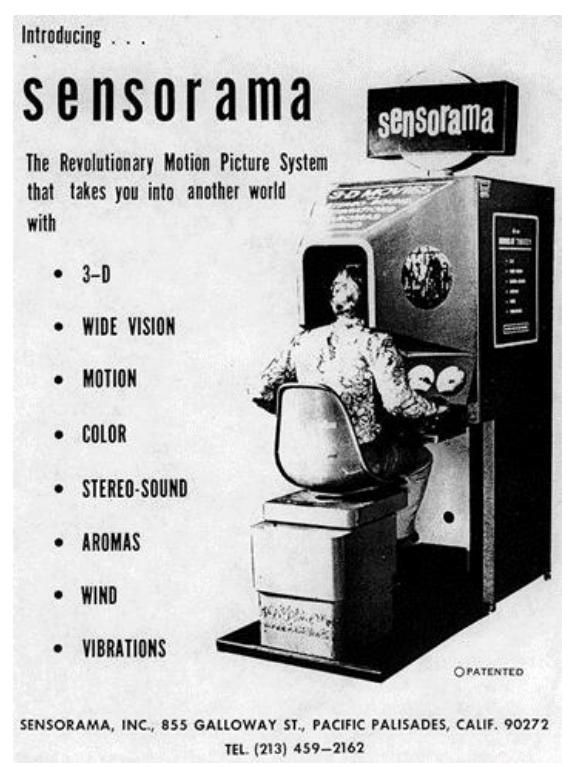

Figura 1: Sensorama. Tomado de: http://www.telepresenceoptions.com/2008/09/theory_and_research_in_hci_mor/

Ciento veinte años después, nos encontramos con una sociedad completamente distinta que se plantea nuevos retos, paradigmas y formas de educar, comunicar y entretener. Una sociedad a la que poco le sorprende una proyección de imágenes planas en movimiento sobre una tela blanca y que está ávida de contenidos de cualquier tipo, para así satisfacer su hambre de conocimientos. 

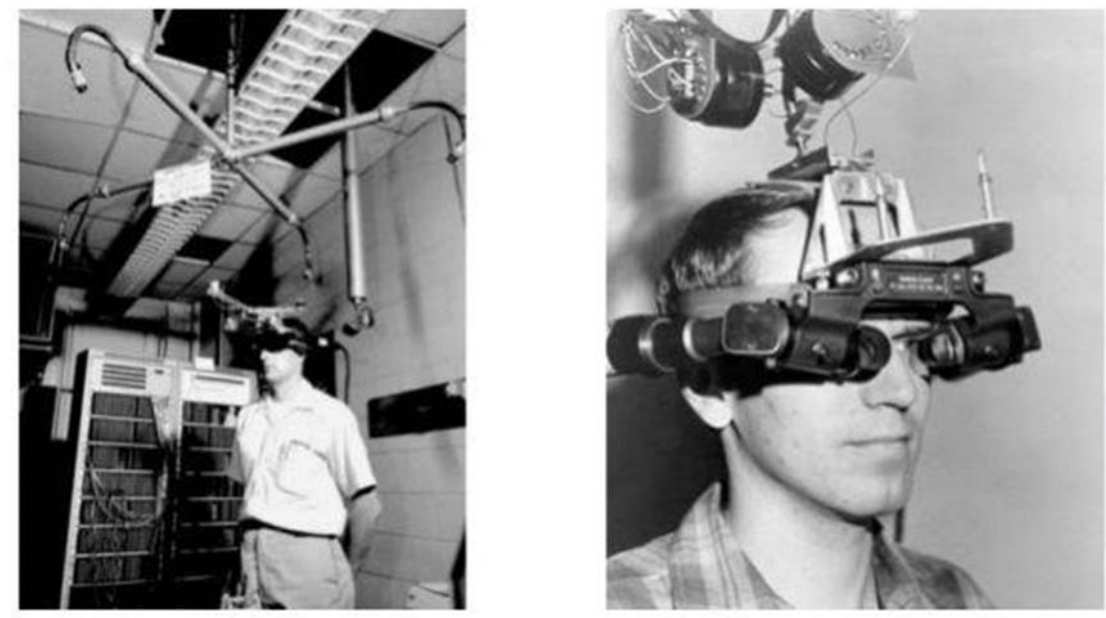

Figura 2: HMD. Tomado de: https://endziz.wordpress.com/2015/04/19/history-of-3d-computer-graphics/

En la segunda década del siglo XXI, cuando, teóricamente, ya se han solventado la mayoría de los problemas de operatividad para una óptima Tecnología de la Información y la Comunicación (Conectividad casi total, dispositivos y aplicaciones accesibles desde el punto económico), el ser humano se enfrenta a una nueva disyuntiva, una matriz determinada por el binomio Plataforma/Contenidos: Cómo transmitir una idea, concepto, historia, con la mayor efectividad y que despierte el mayor interés posible.

En ésta, la Era del Conocimiento y de Revolución Tecnológica, se hace necesaria la investigación y el desarrollo de nuevas estrategias que combinen la percepción de la Realidad "Real" con la Realidad "Virtual", en la que el usuario interactúe y busque su propia experiencia de adquisición de conocimientos y satisfaga su necesidad de conocer nuevas historias y contenidos.

\section{Metodología}

AR Cocoa es una aplicación que nació como un espacio de experimentación con realidad aumentada en el campus de la Universidad San Francisco de Quito. Se planteó el proyecto en la clase de Prácticas en Artes Digitales, realizando co-teaching entre Fabián Varela y Cristina Muñoz. La clase fue conformada por estudiantes en las disciplinas de Interactividad, Animación Digital y Producción de TV y Nuevos Medios.

Como punto de partida, se toman en cuenta dos factores esenciales para el proyecto. El primero consiste en juntar varias disciplinas trabajando, lo que hace posible generar un proyecto integral que requiere varios conocimientos técnicos y destrezas como el manejo de video, animación, programación y diseño. Además, un proyecto de carácter multidisciplinar se nutre de distintas perspectivas, potenciando las posibilidades del mismo.

El segundo factor es la naturaleza del artefacto; AR Cocoa es un producto de investigación. Desde la perspectiva de HCI (Human Computer Interaction), el producto de investigación es una extensión y evolución del prototipo de investigación para apoyar a inquietudes generadas en esta área emergente, como son las experiencias, relaciones y encuentros entre las personas y las tecnologías interactivas (Odom etal.2016). 
Este es un producto en transición o en progreso, que desarrolla nuevos conocimientos desde el primer momento en el que se pone a disposición de las personas. En este sentido, el prototipo se convierte en la única forma de articular conocimiento de manera activa acerca de la interacción de las personas con nuevas tecnologías y de traer a múltiples actores a relacionarse e inclusive a explorar posibilidades de forma más colaborativa.

No existe un propósito definido o utilitario. El fin del proyecto es investigar cómo la tecnología puede mediar entre las personas y sus acciones del día a día. AR Cocoa propone "transformarse en algo" más que "ser algo". Puede quedarse en el campus por un largo período de tiempo que permita a sus creadores hacerse nuevas preguntas y explorar posibilidades sobre su potencial y sus transformaciones a futuro. Tras mencionar estos dos factores acerca de la naturaleza del proyecto, es pertinente detallar y analizar el proceso utilizado, enfocándose principalmente en los retos y oportunidades de construir un producto de investigación.

Para plantear la propuesta a los estudiantes, se identificaron espacios de uso y lugares simbólicos y/o representativos del campus de la universidad. Fue necesario observar y hablar con personas para descubrir qué lugares eran los más icónicos al hablar de la Universidad San Francisco de Quito. Cabe recalcar que el campus de la Universidad es diverso. Definir cuál espacio es el más representativo no es sencillo, ya que son espacios en constante cambio y con distintos significados para las personas que lo utilizan. Fue responsabilidad de los estudiantes decidir qué espacio intervenir.

Una vez definidos los espacios a trabajar, los cuales serán denominados “estaciones"; fue creado un brief para que los estudiantes trabajasen en equipos según la estación seleccionada. Las pautas del proyecto consistieron en investigar sobre la historia detrás del lugar elegido y observar la interacción de las personas en dicho espacio para luego profundizar en la narrativa.

Un paso muy relevante en este proceso fue el uso de metodologías de ideación para plantear narrativas, partiendo de las investigaciones realizadas sobre cada estación. Esta etapa se basó en talleres, utilizando herramientas de Design Thinking, metodología que abarca herramientas de diseño para incentivar la creatividad, dinamizar el diálogo en los equipos e iterar sobre posibles caminos hasta llegar a una idea concreta. Este pensamiento divergente se utiliza para multiplicar las opciones con el fin de crear alternativas. Al probar ideas opuestas entre sí, aumenta la posibilidad que el resultado sea más audaz y creativamente disruptivo (Brown, 2009). Mientras más se utiliza la metodología de Design Thinking, usualmente las personas tienen más aptitud para experimentar nuevas posibilidades, direcciones y soluciones. La diferencia que existe entre los primeros talleres al tercero o cuarto taller, es significativa. El equipo ya se conoce mejor y está más familiarizado con la metodología, las ideas fluyen y se sienten más en confianza en construir sobre las ideas del resto, lo que brinda riqueza a las propuestas.

Para todos los participantes, ésta era la primera vez trabajando con Realidad Aumentada y se consideró importante hacer énfasis en generar una nueva experiencia de la persona con el espacio. Tomando en cuenta el potencial de interacción de esta tecnología, se permitió generar otras capas de diálogo en el espacio a intervenir. Para plantear posibles narrativas e interacciones en el espacio se utilizaron dibujos, storyboards y simulaciones. La intención detrás es que al prototipar se logran resultados más ágiles. Siendo la primera etapa del proceso, vale la pena generar 
ideas rápidas, analizar posibles caminos, experimentar sobre situaciones y tomar decisiones. Mientras más rápido hacemos tangibles nuestras ideas, más rápido podremos evaluar, refinar, e ir a la solución (Brown, 2009).

Una vez definida la propuesta se profundizó en el storytellingde la estación. En esta etapa fue determinante el trabajo multidisciplinar, ya que existió la libertad de plantear objetos animados, video o la mezcla de ambos. Esto se reflejó al momento de trabajar en la propuesta estética ya que al tener menos limitaciones se permitieron jugar y ser consistentes con la narrativa propuesta. Con estos elementos de trabajo, los estudiantes pudieron planificar con facilidad la labor en video, vestuario, sonido, desarrollo de personajes, modelado; también tuvieron claro las limitaciones de la tecnología conducidos por el equipo de interactividad a cargo del estudiante Jorge Flores, quienes investigaron las posibles opciones para realizar estaciones de realidad aumentada.

Este proceso de divergencia y convergencia necesita el espacio y el tiempo para cometer errores. Algunas de las propuestas no funcionaron y fueron imposibles de implementar, en su mayoría porque la ejecución fue muy distinta a la propuesta inicial, ya sea por el tiempo que necesitan para llegar hasta ciertos grados de detalle a nivel de diseño y animación, o porque al implementar por ejemplo juegos que requieren más programación en la estación, los estudiantes no lograron resolverlo con el tiempo que tienen: cuatro meses desde la idea hasta la ejecución. En este sentido, el producto de investigación AR COCOA ha funcionado como un primer prototipo para evaluar errores en el proceso, desarrollar propuestas menos complejas y ejecutables con el tiempo que tenemos, e identificar posibles direcciones para la siguiente generación del prototipo

\section{Resultados}

Desde Enero de 2016, hasta la actualidad, se ha trabajado en trece estaciones y seis nuevas están siendo trabajadas. Se han implementado cinco en el campus y se realizan mejoras y actualización de la aplicación para poder subir cuatro estaciones ya realizadas. Son cuatro las estaciones que no han funcionado.

A continuación se presenta el detalle de cada una de las estaciones propuestas. Las mismas están divididas según las dos generaciones de estudiantes que han trabajado en AR COCOA y una tercera se encuentra en proceso de creación.

\section{Primera generación:}

- Estación Edificio Miguel de Santiago (2 Estudiantes de Animación, 2 Estudiantes de Producción de Televisión y Medios Digitales, 1 Estudiante de Interactividad)

Logline: Un aborigen de la sierra ecuatoriana, nos guía en la narrativa sobre la "Leyenda de Cantuña".

- Estación Einstein (2 Estudiantes de Animación, 2 Estudiantes de Producción de Televisión y Medios Digitales)

Logline: La famosa Chica del Arete de Perla, sonríe y saluda al usuario 
- Estación Teatro (2 Estudiantes de Animación, 2 Estudiantes de Producción de Televisión y Medios Digitales)

Logline: Un personaje de "La Vida es un Sueño" de Calderón de la Barca, recita un pasaje de la obra. Es interrumpido por un dragón quien desciende y escupe fuego sobre el escenario del teatro.

- Estación Pagoda (2 Estudiantes de Animación, 2 Estudiantes de Producción de Televisión y Medios Digitales)

Logline: Un monje budista medita y se multiplica. En medio de la meditación, un huevo se rompe y sale un dragón que vuela alrededor de la pagoda y escupe fuego al usuario de la aplicación

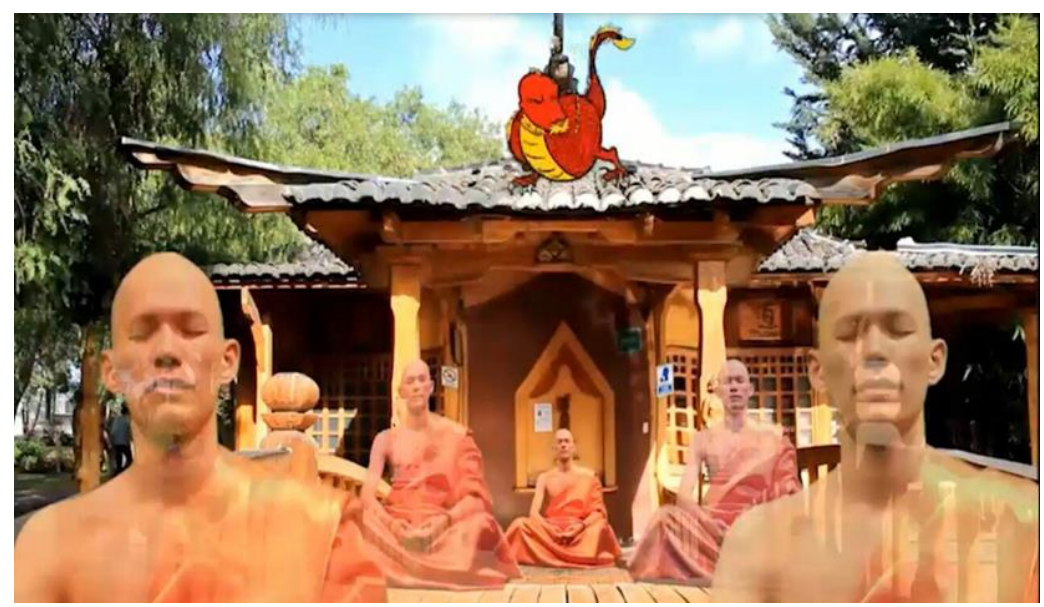

Figura 3: Estación Pagoda

- Estación Biblioteca (2 Estudiantes de Animación, 2 Estudiantes de Producción de Televisión y Medios Digitales, 1 Estudiante de Interactividad)

Logline 1: Primer Piso: Charles Chaplin pide silencio al usuario de la aplicación

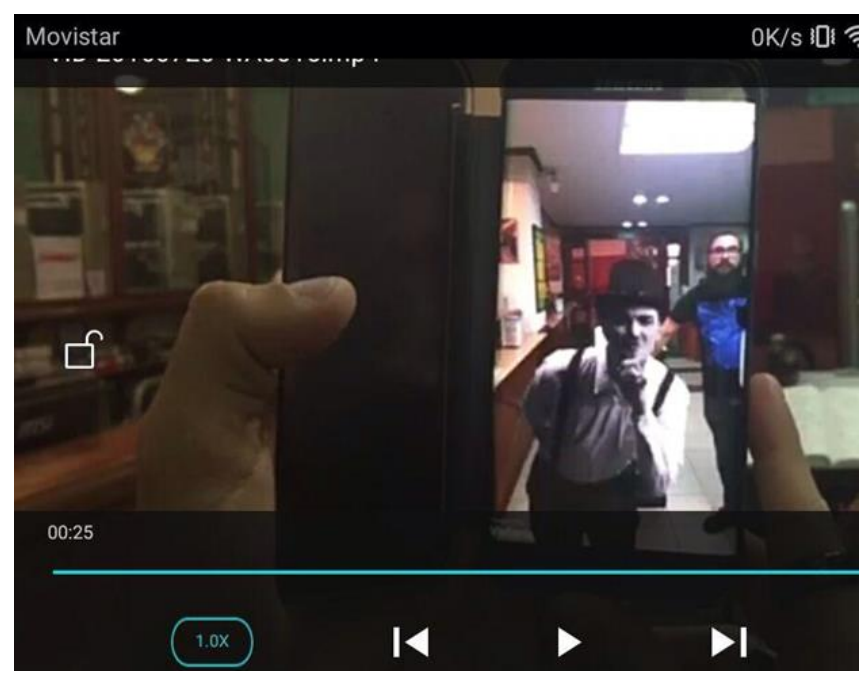

Figura 4: pruebas en Estación Biblioteca, primer piso 
Logline 2: Segundo Piso: Un grupo de libros sale de los estantes y vuelan sobre la sala de estudios de la Biblioteca

- Estación Hall principal (2 Estudiantes de Animación, 2 Estudiantes de Producción de Televisión y Medios Digitales)

Logline: Uno de los leones de piedra del Hall Principal se levanta, salta y se va caminando.

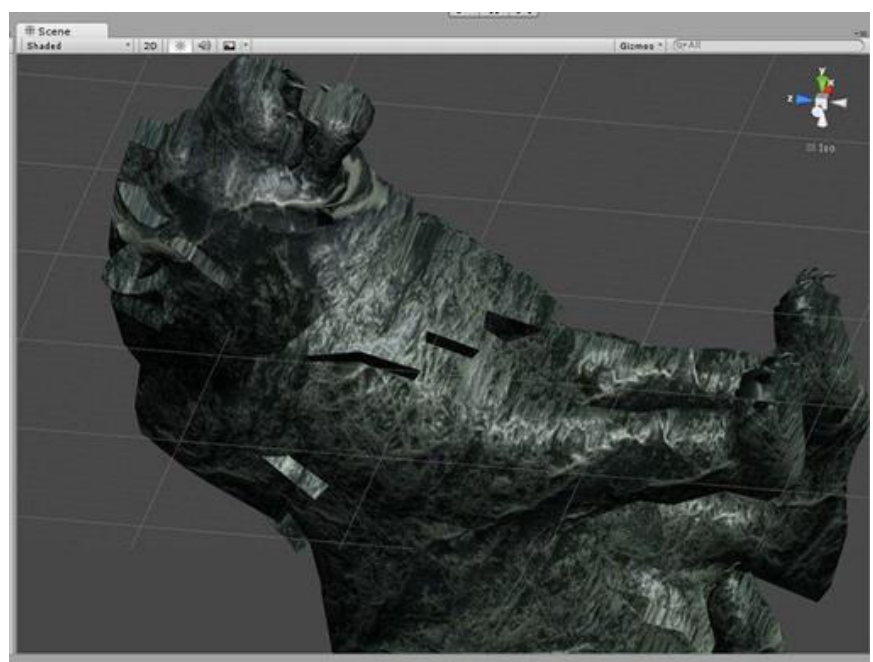

Figura 5: Estación Hall Principal, modelado de león con textura piedra

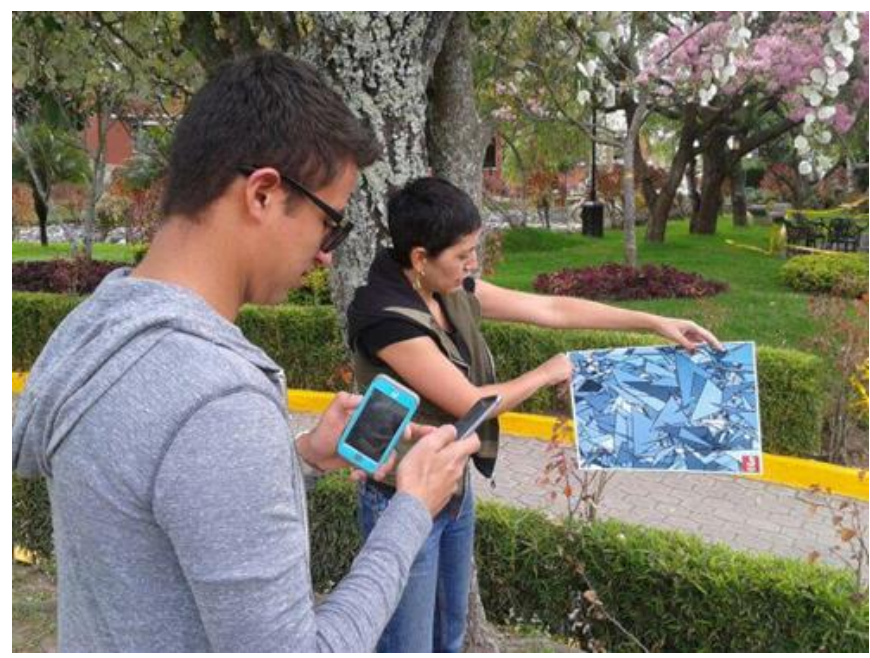

Figura 6: pruebas Android e Iphone 


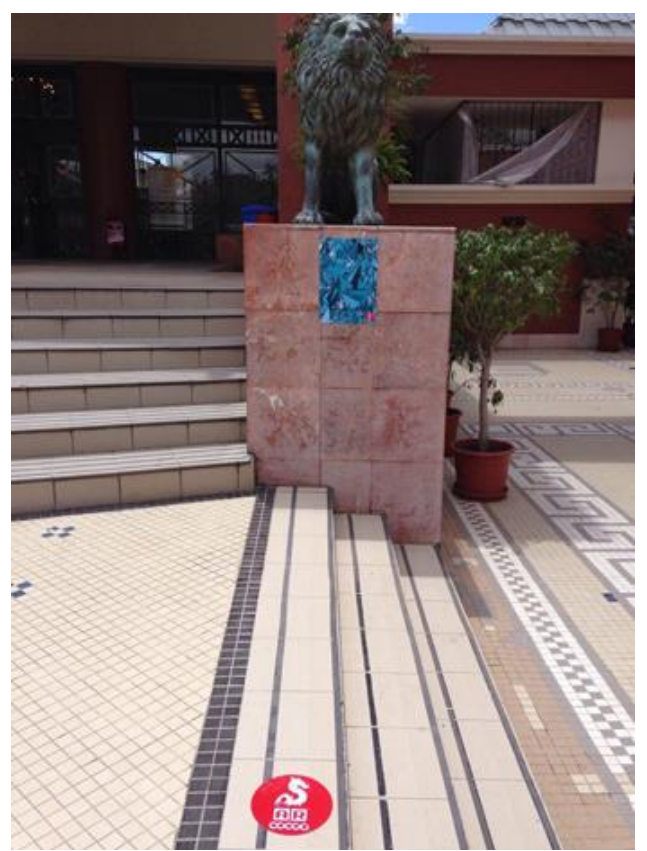

Figura 7: Marcador y punto de ubicación Hall principal

Segunda generación:

- Estación Obelisco (2Estudiantes de Animación y 1 Estudiante de Interactividad)

Logline: Una pareja de amantes sumerios se profesan amor eterno

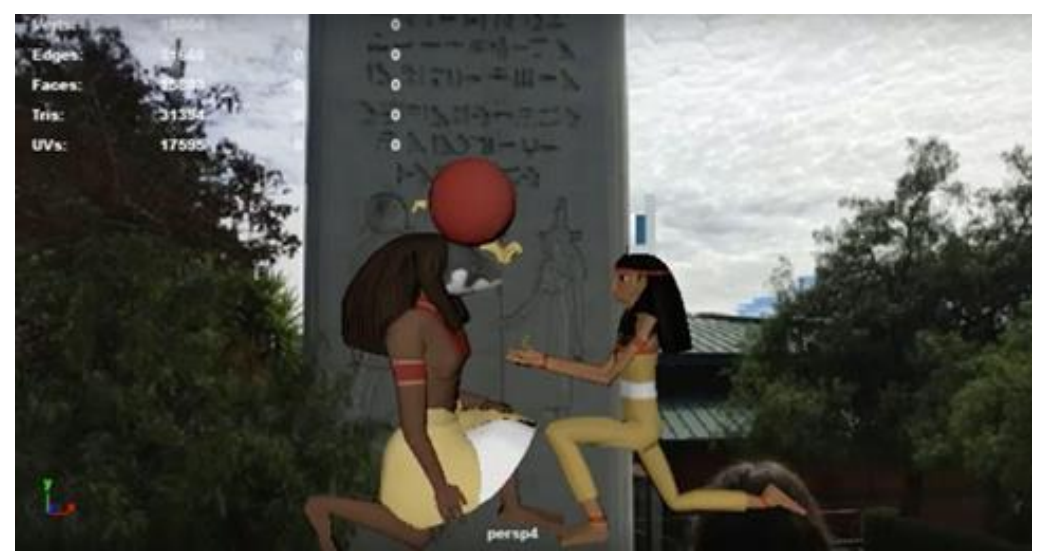

Figura 8: Amantes Sumerios

- Estación Observatorio (2Estudiantes de Animación y 1 Estudiante de Interactividad)

Logline: Un OVNI rapta al canciller de la Universidad y a sus dos perros 

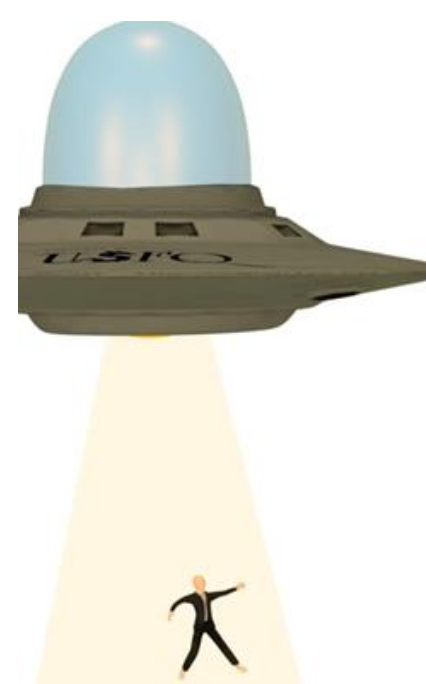

Figura 9: Estación Observatorio

- Estación Laguna (2Estudiantes de Animación y 1 Estudiante de Interactividad)

Logline: Un dragón nada en la laguna, atrapa un pez y luego continúa nadando

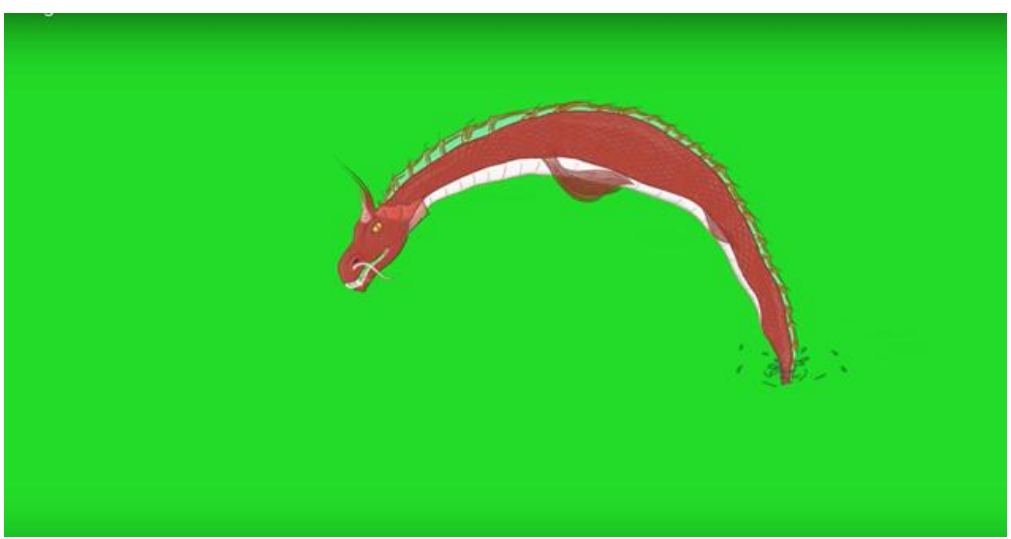

Figura 10: Estación Laguna

- Estación Juego Edificio Hayek (2Estudiantes de Animación y 1 Estudiante de Interactividad)

Logline: El usuario de la aplicación juega memory en los espacios de recreación del edificio Hayek

\section{Tercera Generación}

Actualmente la tercera generación de estudiantes trabajando en AR COCOA está investigando nuevos usos para la aplicación. Entre los distintos equipos exploran cada uno preguntas distintas: ¿Cómo puede esta tecnología ser utilizada en la educación?, ¿Cómo se puede incentivar a los nuevos estudiantes a que exploren el campus? ¿Cómo se puede brindar la información necesaria a estudiantes y padres de familia que no conocen ciertos procesos de 
admisión, cambio de materias, otros? ¿Cómo se puede reflejar el espíritu de la universidad? ¿Cómo es posible explicar a las personas qué hacemos en la carrera de diseño interactivo?

Estas preguntas surgen de la necesidad de investigar el potencial de la tecnología, testear el posible uso que las personas pueden dar a la aplicación y cómo esta puede transformar la manera en que interactuamos con el espacio en el día a día.

\section{El desarrollo de la app}

Para el desarrollo de AR Cocoa, se utilizó Unity,software de código abierto para desarrollo de juegos. Además es utilizado para crear scripts de comportamiento para el entorno 3D como shaders en Javascript y C\#, que permite crear materiales, colores y texturas sobre las animaciones propuestas. También se utilizó una extensión de Unity llamada Vuforia,un kit utilizado para proceso y reconocimiento de la información de realidad aumentada en la aplicación móvil.

Dentro de una aplicación de realidad aumentada se necesitan elementos que sirvan de guía sobre los cuales se reproduce el contenido aumentado. Se utilizó marcadores físicos en lugar de marcadores GPS ya que estos últimos poseen un margen de error que puede variar entre 5 y 15 metros. De igual forma el GPS de los dispositivos móviles no distingue la altura en la que se encuentra la imagen y el equipo necesitaba precisión entre los elementos virtuales y el espacio real.

\section{Los marcadores utilizados en AR Cocoa son patrones únicos en cada estación}

Tanto Vuforia como Unity, se encargan de procesar la información recibida de los marcadores, y de interpretar dichos datos para reproducir los contenidos pertenecientes a cada estación. Buscamos que los marcadores sean parte del entorno, sin distraer al usuario de los contenidos que se reproducen en estas. Se optó por figuras geométricas reconocibles que cambian sus figuras por cada estación. Al ojo de las personas son prácticamente iguales, pero a la lectura de software interpreta el cambio de posición de dichas figuras como una imagen distinta.

Una de las consideraciones a tener en cuenta es que la Realidad Aumentada se enfoca principalmente en elementos de tercera dimensión o "3D”, y no necesariamente en elementos de vídeo, los cuales fueron utilizados en AR COCOA, creando ciertas capas de complejidad al momento de crear la aplicación. Por un lado, se incrementa el peso del archivo, lo cual no es ideal para el usuario, ya que utiliza mayor cantidad de datos del celular. Fue necesario bajar la calidad del video para tener archivos más livianos. Además, al utilizar video y no únicamente animación se debe procesar e integrar los datos; como consecuencia, al validarlos dentro de la aplicación surgieron algunos inconvenientes.

Debido a las consecuencias de utilizar varios medios, en el proceso de validación de AR Cocoa previo al lanzamiento de la aplicación, se realizaron más de 50 iteraciones. Factores como el tamaño del marcador, la hora del día, los colores utilizados, la distancia entre el punto a enfocar y la persona, e incluso la calidad de señal para la conexión a los contenidos son pruebas altamente necesarias para asegurar el buen funcionamiento de la aplicación y potenciar el reconocimiento de la misma. En ciertas estaciones, se buscaba que los videos contaran con un tamaño enteramente 
distinto a la referencia del marcador, que en ese momento tenía el tamaño de una hoja A4 ubicada a un poco más de un metro. Dicho propósito generó un desfase entre el tamaño del video y la capa alfa de transparencia que estaba siendo usada para poder eliminar las partes del video que no eran parte de la experiencia. Una vez solucionada la sincronía de los contenidos, una vibración ocurría en el video debido a la distancia que se estaba usando. El desarrollo en Vuforia generalmente implica un rastreo de marcadores para libros, posters, u objetos específicos a distancias cortas con un alto reconocimiento de acuerdo al tamaño. Sin embargo, AR COCOA utiliza entornos completos en lugares reales, por lo que se modifica el código de reconocimiento necesario para el propósito de la aplicación. Simultáneamente, surgió un problema de vibración dentro de los videos, por la distancia a la que se encontraba el usuario, así como también por una pérdida de los puntos guías de los marcadores correspondientes. Esto implicó una serie de nuevas pruebas para poder determinar la distancia máxima a la cual podríamos poner un marcador sin generar la vibración mencionada, además que los marcadores aumentaron su tamaño a un formato A3 para evitar los problemas mencionados.

Todas las adversidades fueron superadas. Sin embargo, queda el aprendizaje de la utilización exclusiva de elementos 3d para facilitar la funcionalidad de la aplicación. Además, es necesario actualizar la aplicación ya que, al utilizar un software de código abierto, si no se actualizan las versiones nuevas, éste empieza a mostrar problemas de vibración y también complejidad al cargar los datos. Actualmente, la App AR Cocoa se encuentra disponible en los mercados de aplicaciones de los Sistemas Operativos para móviles Android y Apple.
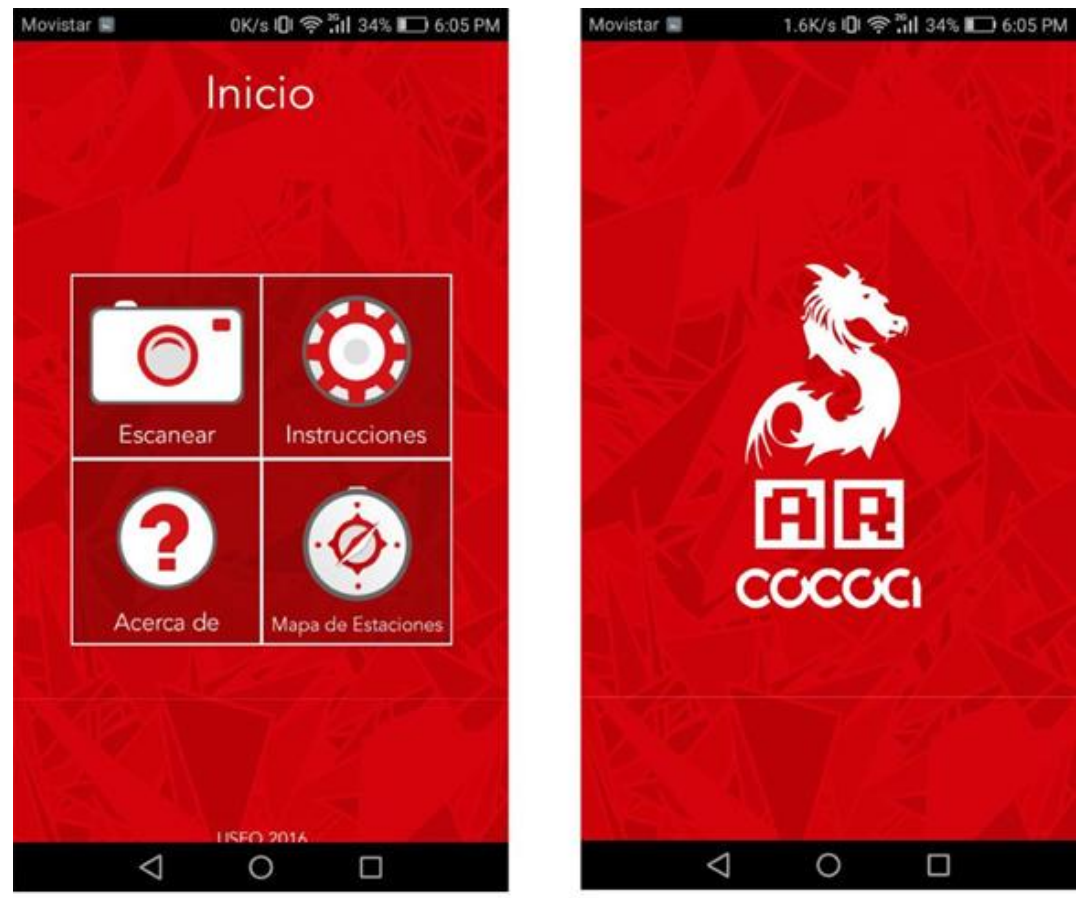

Figuras 11-14: Entorno de la App AR Cocoa

\section{Conclusiones}

Las oportunidades de la Realidad Aumentada como complemento a la experiencia real son infinitas. Es posible hablar de una segunda etapa de la revolución tecnológica. El Consumer Lab 
de la compañía tecnológica Ericsson, publicó un informe en junio de 2017 llamado "La Realidad Fusionada" comprendiendo cómo la realidad virtual y la realidad aumentada podrían transformar la realidad del día a día.

En este informe, basado en 9200 encuestas a personas de Reino Unido, Francia y Estados Unidos, entre otros, arrojó algunos datos interesantes:

7 de cada 10 early adopters consideran que la Realidad Virtual y Aumentada cambiará la vida cotidiana en 6 aspectos fundamentales: educación, medios, trabajo, interacción social, viajes y el comercio. En el campo de la educación, nos enfrentamos a un sin fin de oportunidades. AR Cocoa no escapa de estas proyecciones a futuro. Incluso en el campo de la comunicación y marketing tiene el potencial de extender un medio de comunicación con alternativas más jugadas e interactivas.

La mayor experiencia obtenida ha sido observar las interacciones que la propuesta produce en el público. Para algunas personas la Realidad Aumentada es aún ajena al medio y falta comprensión sobre su uso, lo que se traduce en reforzar la comunicación para que las personas descarguen la aplicación. Otra observación es que esta causa novedad, pero con el tiempo, al no tener algo nuevo, las personas se olvidan de su existencia. Es necesario actualizar la aplicación con nuevas propuestas para generar expectativa y continuidad al proyecto. Por otro lado, para quienes visitan el campus o utilizan la aplicación por primera vez, es una experiencia distinta y se muestran sorprendidas y emocionadas al saber de la propuesta. Esto quiere decir que para las personas es una novedad, pero no las mantiene activamente interesadas, convirtiéndose en una propuesta pasiva.

Una posible opción es crear estímulos para que las personas compartan la información y su experiencia con la realidad aumentada. En este sentido se buscará crear propuestas dentro de la aplicación que sean más inmersivas con el espacio creado. Actualmente AR COCOA trabaja en incorporar opciones que dinamicen el uso de la aplicación. Una opción es introducir la opción "selfie".La intención es que las personas puedan tomarse una foto con la imagen de la realidad aumentada, creando un espacio donde pueden compartir su experiencia.

Otra opción en la que se está trabajando en la actualidad es crear otras interacciones con la aplicación, generando estaciones con funcionalidad, tales como: ubicación de los edificios en el campus, respuestas a procesos internos para los estudiantes nuevos, resolución de acertijos mediante juegos para que los nuevos estudiantes recorran la universidad, muestra del intercambio multidisciplinar entre las distintas carreras, entre otros. El fin es continuar investigando el potencial de la realidad aumentada a través del producto AR Cocoa. Crear nuevas versiones del prototipo permite explorar constantemente qué es esta tecnología y su potencial interferencia en el día a día de las personas.

\section{Bibliografía}

Brown, T. 2009. Change by Design. New York: Harper Business. Páginas 66-92. 
Chen, J. Lackey, S. Virtual, Augmented and Mixed Reality. 9th International Conference, VAMR 2017, Held as Part of HCI International 2017, Vancouver, BC, Canada, July 9-14, 2017.

Cabero Almenara, J., Leiva Olivencia, J. J., \& Moreno Martínez, N. M. (2016). Realidad aumentada y educación: Innovación en contextos formativos. Madrid: Ediciones Octaedro, S.L.

Ericsson Consumer Lab. (2017). Experience shapes mobile customer loyalty. Understanding the impact of connectivity experience on smartphone user's loyalty to their operator. Recuperado de: https://www.ericsson.com

González, C. Vallejo, D. Albusac, J. Castro, J. Realidad Aumentada. Un Enfoque Práctico con ARToolkit y Blender. Bubok Publishing S.L. 2014.

Huang, W., Alem, L., \& Livingston, M. A. (2013;2014;2012;). Human factors in augmented reality environments (2013;1; ed.). New York, NY: Springer Verlag. doi:10.1007/978-1-46144205-9

Kipper, G., Rampolla, J., \& Books24x7, I. (2013;2012;). Augmented reality: An emerging technologies guide to AR (First ed.). US: Syngress Media Incorporated.

Odom, W., Wakkary R., Lim Y., Desjardins A., Hengeveld B., and Banks R. (2016). From Research Prototype to Research Product. ACM New York.

Miglino, O., Nigrelli, M. L., \& Sica, L. S. (2013). Videojuegos de rol, simulaciones por ordenador, robots y realidad aumentada como nuevas tecnologías para el aprendizaje: Guía para profesores, educadores y formadores.

Madrid: Universitat Jaume I. Servei de Comunicació i Publicacions.

Mullen, T., \& Books24x7, I. (2011). Prototyping augmented reality (1. Aufl.;1; ed.). Hoboken: Sybex.

Prendes C. Realidad aumentada y educación: análisis de experiencias prácticas Pixel-Bit. Revista de Medios y Educación, núm. 46, enero-junio, 2015, pp. 187-203 Universidad de Sevilla. Sevilla, España

Shumaker, Randall.editor. Virtual, Augmented and Mixed Reality. Systems and Applications 5th International Conference, VAMR 2013, Held as Part of HCI International 2013, Las Vegas, NV, USA, July 21-26, 2013, Proceedings, Part II

Sora, C. (2016). Temporalidades digitales: Análisis del tiempo en los new media y las narrativas interactivas. Barcelona: Editorial UOC.

Unity. (s.f) Obtenido de https://unity3d.com/ 
Vuforia. (2017) Obtenido de https://www.vuforia.com/ 